\title{
Valoração ambiental em áreas de preservação permanente na bacia hidrográfica do Rio Passaúna, Estado do Paraná
}

\author{
Environmental valuation of permanent preservation areas of the Passaúna river watershed, \\ Paraná State
}

\section{Roni Djeison Ansolin ${ }^{1 *}$, Kênia Samara Mourão Santos ${ }^{1}$, Ana Paula Donicht Fernandes ${ }^{2} \&$ Franco Schinato $^{3}$}

${ }^{1}$ Universidade Federal do Paraná, Curitiba, PR, Brasil. *Autor para correspondência: roni_ansolin@hotmail.com.

${ }^{2}$ Universidade Federal Rural da Amazônia, Campus Capitão Poço, PA, Brasil.

${ }^{3}$ Instituto Federal de Santa Catarina, Canoinhas, SC, Brasil.

Submissão: 09/02/2017 / Aceite: 09/02/2018

\begin{abstract}
RESUMO
As áreas de preservação permanentes (APPs), sobretudo aquelas situadas ao longo das margens dos corpos hídricos, contribuem diretamente para a manutenção e promoção da qualidade no ciclo hidrológico. Tendo em vista que a valoração ambiental é considerada uma importante ferramenta metodológica para subsidiar a tomada de decisões no uso dos recursos naturais, o presente estudo teve como objetivo: quantificar as APPs nas nascentes e margens de cursos d'água, antes e após a mudança no código florestal; e estimar o valor econômico das APPs consideradas prioritárias. A pesquisa foi conduzida na bacia hidrográfica do rio Passaúna, localizada no município de Curitiba. Os dados do Sistema de Informações Geográficas (SIG) foram disponibilizados pelo Instituto de Águas do Paraná. Foi utilizado o método de "custo de oportunidade" para valoração econômica combinado as áreas prioritárias. As APPs foram classificadas em nível de importância, de acordo com a sua localização e declividade. De acordo com os limites do novo código florestal (2012), pode haver uma redução de 1.077,1 ha de APP em torno das margens de rios, nascentes e lagos. Com relação ao uso e ocupação do solo, predominam as atividades agrícolas, representando $46,11 \%$ da área total. Identificaram-se 204,9 e 872,2 hectares de áreas com alta e baixa prioridade, respectivamente. $O$ valor econômico estimado para a manutenção das áreas passíveis de supressão é de $\mathrm{R} \$ 945,00$ ha/ano. Conclui-se que o mapa elaborado juntamente com a valoração ambiental pode ser uma referência para a tomada de decisões visando à gestão ambiental, bem como para implantação de políticas públicas, tais como pagamentos por serviços ambientais, de modo a incentivar produtores rurais a conservar áreas com importantes funções ambientais.
\end{abstract}

PALAVRAS-CHAVE: pagamentos por serviços ambientais, código florestal, sistema de informações geográficas, políticas públicas.

\begin{abstract}
Permanent Preservation Areas (PPA), especially around river banks, springs and lakes, contribute significantly to the quality of the hydrological cycle. Environmental valuation is considered an important methodological tool to subsidize decision-making for the natural resources use. This study aimed to quantify the area of PPA's in springs and margins of water courses, before and after the change in the Forest Code; and to estimate the economic value of priorities PPA's. The study was conducted in the Passaúna River Watershed, located in the city of Curitiba. The GIS data were made available by the Water Institute of Paraná State. The "opportunity cost" method was used for economic valuation combined with priorities areas. Using the limits of the new Forest Code (2012) there may be a reduction of 1,077.1 ha in PPA's around river banks, springs and lakes. The agricultural area is predominant, representing $46.11 \%$ of the total area. It was identified 204.9 and 872.2 hectares areas as high and low priority areas respectively. The estimated economic value for the maintenance of these areas is $R \$ 945.00$ ha/year. It is concluded that the presented map and the environmental valuation are an important reference for decision-making by public managers, as well for the public policies implementation, as payment for ecosystem services, which reward and encourage rural producers to conserve forest areas with important environmental functions.
\end{abstract}

KEYWORDS: payments for ecosystem services, forestry code, geographic information system, public policies. 


\section{INTRODUÇÃO}

A agenda ambiental é um assunto de destaque atualmente, com amplitude internacional, sobretudo em função dos efeitos provenientes das relações dos seres humanos com a natureza. Entretanto, DALY (1991) constata que o homem, ao explorar a terra de forma rudimentar, seja por desconhecimento técnico, seja pela exploração puramente econômica ou pela utilização das tecnologias de forma inconsequente, buscou o chamado crescimento econômico a qualquer preço, principalmente no último século.

O pesquisador NADIR JÚNIOR (2006) enfatiza que as políticas de recuperação e conservação ambiental devem estar sempre comprometidas com a responsabilidade social e econômica dos principais atores envolvidos, neste caso os produtores rurais. Destes, muitos detém somente suas propriedades como única ou maior fonte de renda, e, sob esta ótica, decidem aderir a programas ambientais quando esses não comprometem suas fontes de renda, ou quando vislumbram ganhos econômicos e valorização de seus ativos, ainda que estejam conscientes e compreendam questões tais como sustentabilidade e ecologia. JUSTINIANO (2010) refere que é possível conservar, mas é preciso gerar renda para o empreendedor rural, principalmente aquela oriunda dos serviços e produtos gerados pelos recursos ambientais manejados com práticas ecologicamente corretas.

As Áreas de Preservação Permanente (APPs), previstas no Código Florestal de 1965 e 2012, têm a função precípua de proteger o meio ambiente e assegurar-lhe a perpetuidade e o seu papel de prover 0 bem-estar das populações humanas. Entretanto, a partir de 2012, com a atualização da legislação ambiental, é possível reduzir essas áreas em alguns biomas.

Os benefícios gerados pelas APPs, principalmente no entorno das margens de rios, nascentes e lagos, contribuem significativamente na qualidade do ciclo hidrológico, que tem seus processos ecológicos ampliados quando em conexão com outros fragmentos de florestas, em uma bacia hidrográfica. Essa premissa pode ser evidenciada pelos resultados do estudo realizado por ERNST (2004), que analisou 27 regiões americanas fornecedoras de água e concluiu que os custos de tratamento em bacias com pelo menos $60 \%$ de suas áreas cobertas por florestas foram metade dos mesmos custos verificados em bacias com $30 \%$ de florestas e um terço do custo identificado em bacias com 10\% de áreas florestadas.

Entre os serviços ecossistêmicos prestados pelas bacias hidrográficas, especial atenção deve ser dada aos serviços hidrológicos, constituídos pelos serviços de purificação e filtragem da água, regulação dos fluxos estacionais, controle da erosão e dos sedimentos e preservação de hábitats naturais. Bacias hidrográficas com alta proporção de áreas florestadas possuem uma maior capacidade de moderação de escoamento superficial, bem como de purificação de recursos hídricos (POSTEL \& THOMPSON JR. 2005).

Apesar da importância de considerar as bacias hidrográficas como unidades básicas de análise e elaboração de políticas ambientais, ainda não é frequente o estudo das trajetórias dos fluxos de serviços ecossistêmicos nas mesmas. Em termos de valor dos serviços ecossistêmicos, novamente são poucos os estudos (KREUTER et al. 2001, FREITAS et al. 2010, RIBEIRO et al. 2010, VILAR et al. 2010, ANDRADE et al. 2012) que tentaram captar a relação entre a dinâmica do uso do solo em bacias hidrográficas e a trajetória dos serviços ecossistêmicos.

Dentre o instrumental oferecido pela teoria econômica para a análise de problemas ambientais, destaca-se a valoração ambiental, que pode ser combinada com o uso de sistema de informações geográficas, sendo importante ferramenta metodológica para subsidiar a tomada de decisões no uso dos recursos naturais. Conhecer o valor dos serviços ecossistêmicos é útil para sua efetiva gestão, o que, em alguns casos, pode incluir incentivos econômicos para sua preservação. Todavia, deve-se ter em mente, ainda, que valorar os serviços ecossistêmicos não é o mesmo que "comoditificá-los" para negociação em mercados privados.

DAILY et al. (2000) colocam ainda que a valoração não é a solução para o problema da preservação do capital natural, nem um fim em si mesmo. A valoração é apenas um modo de organização das informações necessárias para guiar um processo de tomada de decisões envolvendo o uso dos "ativos" do capital natural, exercida em conjunto com instrumentos financeiros e arranjos institucionais que permitam aos indivíduos capturar o valor dos "ativos" dos ecossistemas.

A fim de fornecer um exemplo prático de como a valoração dos serviços ecossistêmicos pode subsidiar o debate sobre políticas ambientais, este artigo traz um estudo de caso da bacia hidrográfica do rio Passaúna, localizada no Estado do Paraná, na mesorregião de Curitiba, analisando-se os impactos da dinâmica de uso da terra sobre os valores dos serviços ecossistêmicos.

O presente estudo tem como objetivo: i) quantificar a área das APPs nas nascentes e margens de cursos d'água, antes (1965) e após (2012) a mudança no Código Florestal e, ii) estimar o valor econômico das APPs prioritárias para mantê-las conservadas. 


\section{MATERIAIS E MÉTODOS}

\section{Descrição da área de estudo}

A Bacia Hidrográfica Rio Passaúna está localizada na região do Alto Iguaçu, entre as sub-bacias do rio Verde e Barigui, engloba os municípios de Almirante Tamandaré, Campo Magro, Campo Largo, Curitiba e Araucária (SAUNITI et al. 2004). Possui área total de drenagem de, aproximadamente, $216,68 \mathrm{~km}^{2}$. Segundo o sistema de Köppen, o clima predominante corresponde à classificação do tipo Cfb, mesotérmico úmido, sem estação seca, com temperatura média do mês mais quente inferior a $22{ }^{\circ} \mathrm{C}$ e com verões amenos. A precipitação mensal média é de 133,06 mm, enquanto a precipitação anual média é de 1571,0 $\mathrm{mm}$. Sua vegetação é formada por campos naturais, divididos em dois tipos de estepes gramíneo-lenhosas, campos secos e campos úmidos (várzeas); Floresta Ombrófila Mista, também dividida em duas classes; Floresta Ombrófila Mista Montana e a Floresta Ombrófila Mista Aluvial (SILVA FILHO 2010).

\section{Avaliação do uso do solo e hidrografia}

Para avaliação da paisagem da bacia hidrográfica do rio Passaúna, mapearam-se de forma agrupada o uso do solo e a área total de drenagem. Para as análises desse estudo consideraram-se as seguintes classes: "área agrícola", "área urbana", "vegetação" (florestas), "solo exposto" e "água", conforme apresentado na Tabela 1.

Tabela 1. Classificação de uso do solo da Bacia Hidrográfica do Rio Passaúna.

Table 1. Land use classification of the Passaúna river watershed.

\begin{tabular}{lccccc}
\hline Água (ha) & Solo exposto (ha) & Vegetação (ha) & Área agrícola (ha) & Área urbana (ha) & Total (ha) \\
\hline $1.057,13$ & 145,63 & $8.847,45$ & $9.990,26$ & $1.627,83$ & $21.668,33$ \\
$4,88 \%$ & $0,68 \%$ & $40,81 \%$ & $46,11 \%$ & $7,52 \%$ & $100 \%$ \\
\hline
\end{tabular}

Definiu-se "área agrícola" o agrupamento das seguintes subclasses: toda área produtiva, área construída no perímetro rural, pastagens e campos. Já "área urbana" compreende toda área edificada no perímetro urbano. A componente "vegetação" corresponde estritamente à área, ou seja, vegetação arbórea e arbustiva, separando a classe de "solo exposto", que caracteriza áreas de mineração e degradadas. E por fim a classe "água", composta pela hidrografia da bacia, rios, nascente, lagos e dutos de drenagem.

A bacia de drenagem do rio Passaúna ocupa uma área de $849 \mathrm{~km}^{2}$, formando um mosaico de ramificações hidrográficas (Figura 1A) que produz cerca $2.000 \mathrm{l} / \mathrm{s}$ (SUDERHSA 2002) para o sistema o de abastecimento.

A identificação e a quantificação das classes de uso do solo podem ser observadas no mapa temático de uso do solo (Tabela 1; Figura 1B), sendo predominante o uso para áreas agrícolas na bacia hidrográfica.

\section{Delimitação e quantificação das áreas de preservação permanente}

Para delimitar e quantificar a possível redução da superfície das Áreas de Preservação Permanente, após a alteração do Código Florestal, Lei 12.651/2012, foram utilizadas as bases de dados vetorizadas referentes ao ano 2000, de hidrografia, altimetria e uso do solo, disponíveis na "biblioteca virtual" do INSTITUTO DAS ÁGUAS DO PARANÁ (2000). As modificações ocorridas de acordo com a legislação, nas APPs nas margens de rios, nascentes e lagos, podem ser observadas na Tabela 2.

Foram elaborados mapas temáticos de uso do solo, hidrografia e Áreas de Preservação permanente. As APPs foram delimitadas, em consonância com o disposto nos códigos florestais de 1965 e 2012 (BRASIL 1965, 2012), somente para áreas do entorno das nascentes e as suas áreas de contribuição e margens dos cursos d'água. Assim, seguiu-se com a demarcação das APPs e a análise da possível redução da área florestal no entorno dos cursos d'água, nascentes e lagos.

Área "agrícola" representa $46,11 \%$ da área total da cobertura da bacia. Já a classe de uso "vegetação", que corresponde à área de florestas, ocupa 40,81\% (8.847,45 ha) da área total e detém a segunda maior cobertura.

\section{Valoração econômica das APPs}

Dentro dos métodos indiretos de valoração é possível utilizar diferentes metodologias, como a de custo de oportunidade. O custo de oportunidade reflete as perdas econômicas da população em razão das restrições de uso dos recursos ambientais, sendo este custo transformado em valor ambiental do bem (MOTTA 1998). 


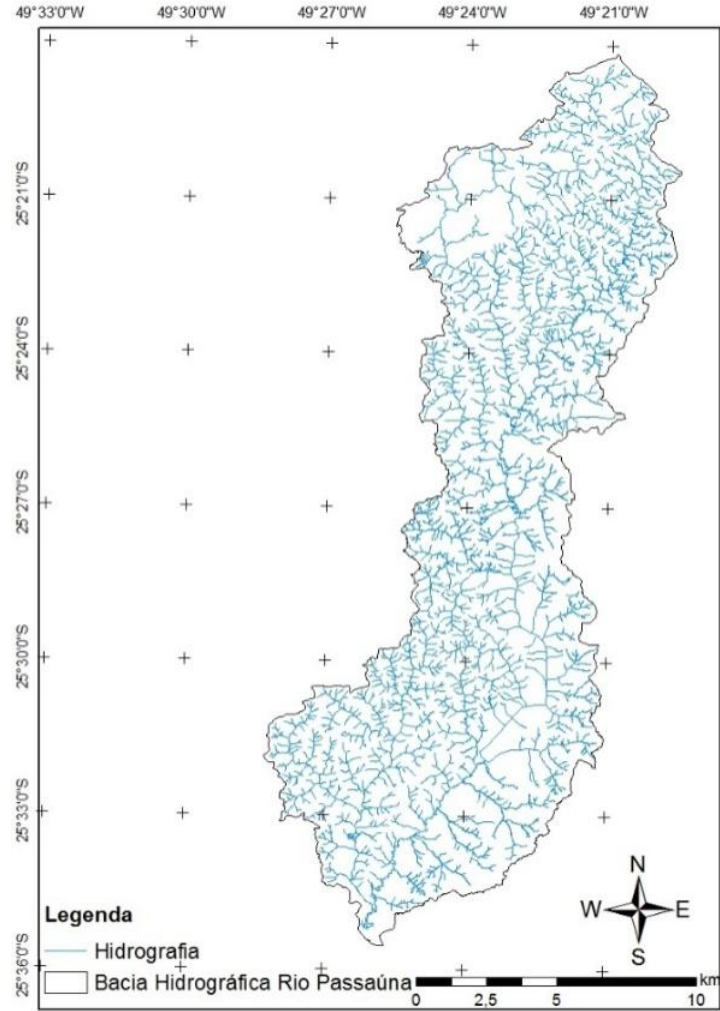

(A)

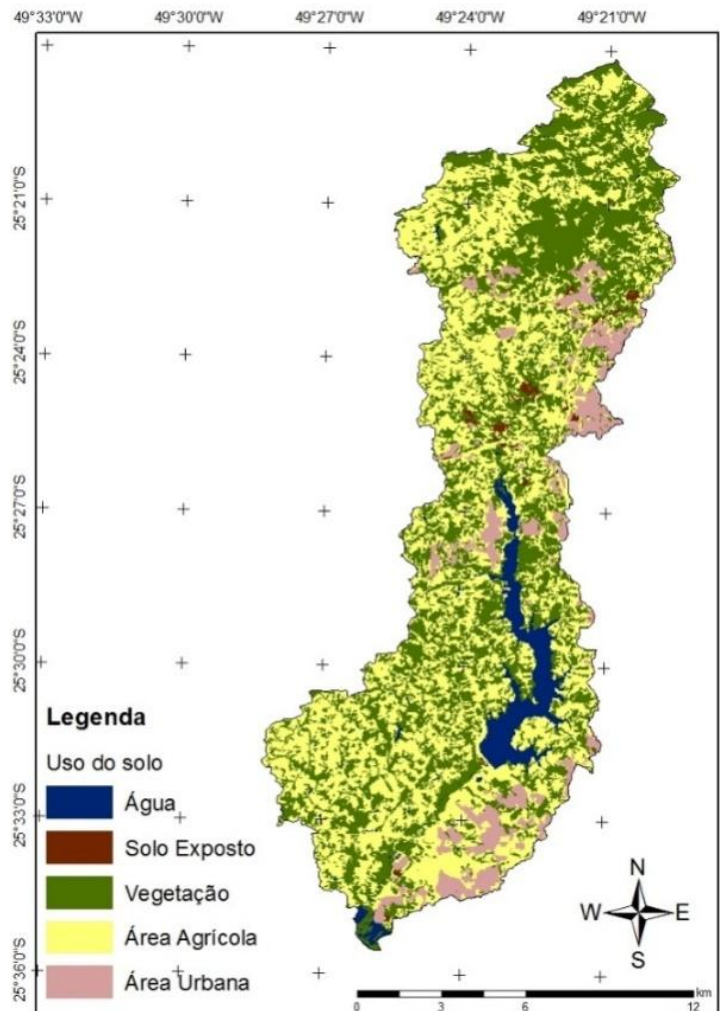

(B)

Fonte: Instituto Águas do Paraná

Figura 1. Mapa de caracterização hidrográfica $(A)$ e de uso do solo (B) da Bacia Hidrográfica do Rio Passaúna.

Figure 1. Hydrographic characterization map $(A)$ and land use $(B)$ of the Passaúna river watershed.

Tabela 2. Alterações nas Áreas de Preservação Permanente de acordo com o Código Florestal de 1965 e 2012.

Table 2. Permanent preservation areas modifications according to the Forest Code of 1965 and 2012.

\begin{tabular}{l|c|c}
\hline Largura do rio $(\mathrm{m})$ & APPs $(\mathrm{m})-$ Lei 4.771/1965 & APPs $(\mathrm{m})-$ Lei 12651/2012 \\
\hline$<10$ & 30 & $15^{\star}$ \\
10 a 50 & 50 & 50 \\
50 a 200 & 100 & 100 \\
200 a 600 & 200 & 200 \\
$>600$ & 500 & 500 \\
Nascentes & 50 & 50 \\
Lagos (1 a 20 ha) & 50 & $30^{*}$ \\
Lagos em área urbana & 30 & 30 \\
\hline
\end{tabular}

*área consolidada.

Para o presente estudo utilizou-se o valor de custo de oportunidade proposto pelo Governo do Estado de Santa Catariana (SANTA CATARINA 2010), segundo o qual cada hectare de floresta corresponde a 30 sacas $(60 \mathrm{~kg})$ de milho/ano, com o objetivo de valorar as áreas que deixaram de ser Áreas de Preservação Permanente após a alteração do Código Florestal em 2012. O valor médio da saca de milho ha/ano para a região de Curitiba, convertido em valor monetário conforme a média anual disponibilizada pelo DEPARTAMENTO DE ECONOMIA RURAL (2016) equivale a $R \$ 31,50$.

Visando contribuir com o planejamento na bacia hidrográfica, a análise priorizou a valoração ambiental para áreas com maior importância, de acordo com a localização da APP e sua declividade. Assim, consideraram-se, em ordem prioritária, as áreas com maior grau de importância, ou seja, de maior valor, apresentadas na Tabela 3, conforme proposto por FRANCISCO (2006) e SPÖRL \& ROSS (2004). 
Tabela 3. Parâmetros de classificação para as áreas prioritárias.

Table 3. Classification parameters of the priority areas.

\begin{tabular}{lcc}
\hline Classe de declividade (\%) & Localização & Grau de importância \\
\hline $0-6$ & Margem de rio & 1 \\
$6-12$ & Nascente & 2 \\
$12-20$ & - & 3 \\
$20-45$ & - & 4 \\
$>45$ & - & 5 \\
\hline
\end{tabular}

Fonte: adaptada pelo autor (FRANCISCO 2006, SPÖRL \& ROSS 2004).

As áreas de nascentes têm papel fundamental na produção de água e a sua conservação deve ser prioritária, sobretudo quando combinada a altas declividades. Assim, em casos de investimentos buscando a conservação dos recursos hídricos, estas devem ser consideradas áreas prioritárias. Na sequência deste estudo, foram priorizadas áreas referentes às margens de rios e lagos e entorno de canais de drenagem.

\section{RESULTADOS E DISCUSSÃO}

A região da Bacia Hidrográfica do Rio Passaúna possui grandes potencialidades, em razão da riqueza de recursos naturais e beleza cênica. Com relação aos recursos hídricos, estes são abundantes, sendo uma região extremamente relevante, abrigando importantes nascentes. Assim, a sistematização dos dados é de suma importância para a criação de parcerias institucionais na busca de melhorias a fim de contribuir para a qualidade ambiental da bacia hidrográfica.

A Figura 2 apresenta como resultado a delimitação das APPs localizadas próximo de cursos d'água, nascentes e lagos, identificadas na área de estudo. Pelo novo Código Florestal de 2012, atualmente as APPs ocupam uma área de 1.864,64 ha, sendo que com base no Código Florestal de 1965 a área de preservação permanente compreendia 2.942,64 ha.

Ao considerar a possibilidade de haver a redução das APPs após a atualização do código florestal em 2012, verifica-se uma perda de 1.077,1 ha de áreas com floresta, o que corresponde a uma perda de $36,63 \%$ dessa cobertura vegetal (Tabela 4 ).

A preservação dos fragmentos florestais é de grande importância, principalmente dos que estão próximos aos cursos d'água da bacia hidrográfica do Rio Passaúna, por exercer a função de abastecimento hídrico dos mananciais da região metropolitana de Curitiba (PR). Dentre muitos serviços e benefícios resultantes dessa cobertura florestal há a proteção ao solo contra o impacto direto das gotas de chuva, diminuindo a velocidade de escoamento superficial e favorecendo a infiltração de água no solo. Atua também como uma forma de "esponja", contribuindo para o processo de purificação da água até chegar nos rios, lagos e nascentes.

Entretanto, após a atualização legal do Código Florestal de 1965, em 2012, os proprietários rurais com até 4 módulos fiscais podem optar em fazer a redução da área de preservação florestal, por meio de projetos junto aos órgãos ambientais responsáveis.

Para melhor identificar essas áreas, elaborou-se o mapa das APPs prioritárias, representado na Figura 3, destacando dois níveis de prioridade, média (1) e alta (2).

De acordo com a declividade e o tipo de APP, foi gerado um mapa temático, indicando os pontos prioritários para preservação. Para esta bacia a escala variou de 1 a 2 , sendo que áreas com alta prioridade (2) representam classes de declividade acentuada $(<20 \%)$ combinada com APP tipo nascente. Já escala média (1) representa áreas localizadas em margens de rios e em áreas de baixa a média declividade (0$20 \%$ ). As áreas de nascentes têm um papel fundamental na produção de água e a sua conservação deve ser prioritária, bem como as áreas situadas às margens de rios.

Ao analisar o mapa também foi possível verificar as APPs que estão em conflitos com outros usos, ou em desacordo com a legislação ambiental, áreas que supostamente deveriam ser APPs, entretanto não estão adequadas. Tendo em vista que o objetivo do trabalho é quantificar somente as áreas com vegetação, outros usos não foram considerados. Entretanto, esses conflitos apresentados no mapa podem também ser interpretados como resultados, para análise por meio dos gestores públicos, facilitando o planejamento e condução de programas de recuperação ambiental.

De acordo com o cenário apresentado, fica evidente a necessidade de um cuidado especial dessas áreas, o qual inclui as Áreas de Preservação Permanente, para que estas possam ser geridas de forma sustentável e tenham suas funções ecológicas resguardadas. 


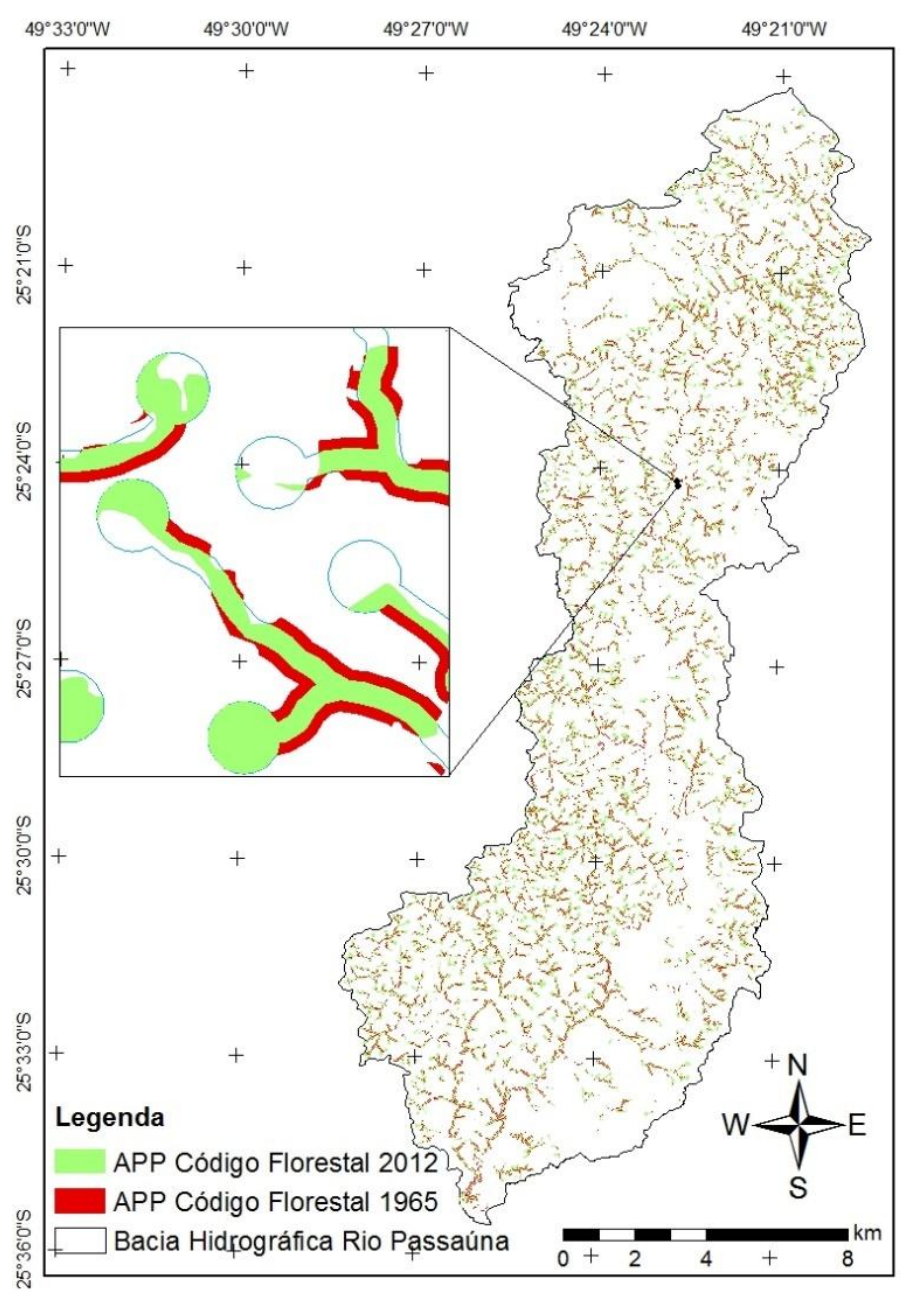

Figura 2. Mapa de delimitação das APPs na Bacia Hidrográfica do Rio Passaúna.

Figure 2. Permanente preservation areas delimitation map of the Passaúna River watershed.

Tabela 4. Composição da área de preservação permanente na Bacia Hidrográfica do Rio Passaúna.

Table 4. Permanent preservation area typesetting of the Passaúna river watershed.

\begin{tabular}{cccc}
\hline Área total (ha) & Área de APPs antiga* $^{*}$ (ha) & Área de APPs atual ${ }^{*}$ (ha) & Área possível de redução* (ha) \\
\hline $21.668,33$ & $2.942,04$ & $1.864,94$ & $1.077,1$
\end{tabular}

${ }^{*}$ Considerou-se somente área florestal, com base nos dados do Instituto Águas do Paraná.

Buscando obter dados econômicos como referência para a manutenção das áreas florestais e também de seus serviços ecossistêmicos produzidos, aplicou-se a metodologia de valoração ambiental de "custo de oportunidade", utilizada pelo estado de SANTA CATARINA (2010), na qual os valores econômicos encontrados paras as mesmas estão apresentados na Tabela 5.

As informações combinadas no mapa indicam um total de 204,9 hectares de áreas com alta prioridade para conservação, ou seja, áreas que apresentam maior fragilidade com relação à proteção dos recursos hídricos, localizadas em áreas com elevadas declividades, sendo estas principalmente nascentes. Também são áreas que apresentam maior função ambiental dentro da bacia hidrográfica, como recarga d'água e produção de serviços ecossistêmicos, de modo que projetos de pagamentos por serviços ambientais são uma alternativa para a manutenção e a melhoria da qualidade ambiental na bacia hidrográfica.

Contudo, verifica-se que a maior área de cobertura florestal na bacia está representada pela classe prioritária média, porém não menos importante. Essas áreas também contribuem para a dinâmica ambiental e ecológica dentro da bacia, embora estejam associadas à classe de declividades menores e próximo a margem de rios. Ademais, é importante destacar que a bonificação monetária aqui apresentada se torna realidade somente por meio da implantação de um programa de pagamento por serviços ambientais. Este programa deve atuar como um mecanismo de estímulo para os proprietários rurais preservarem suas áreas. 


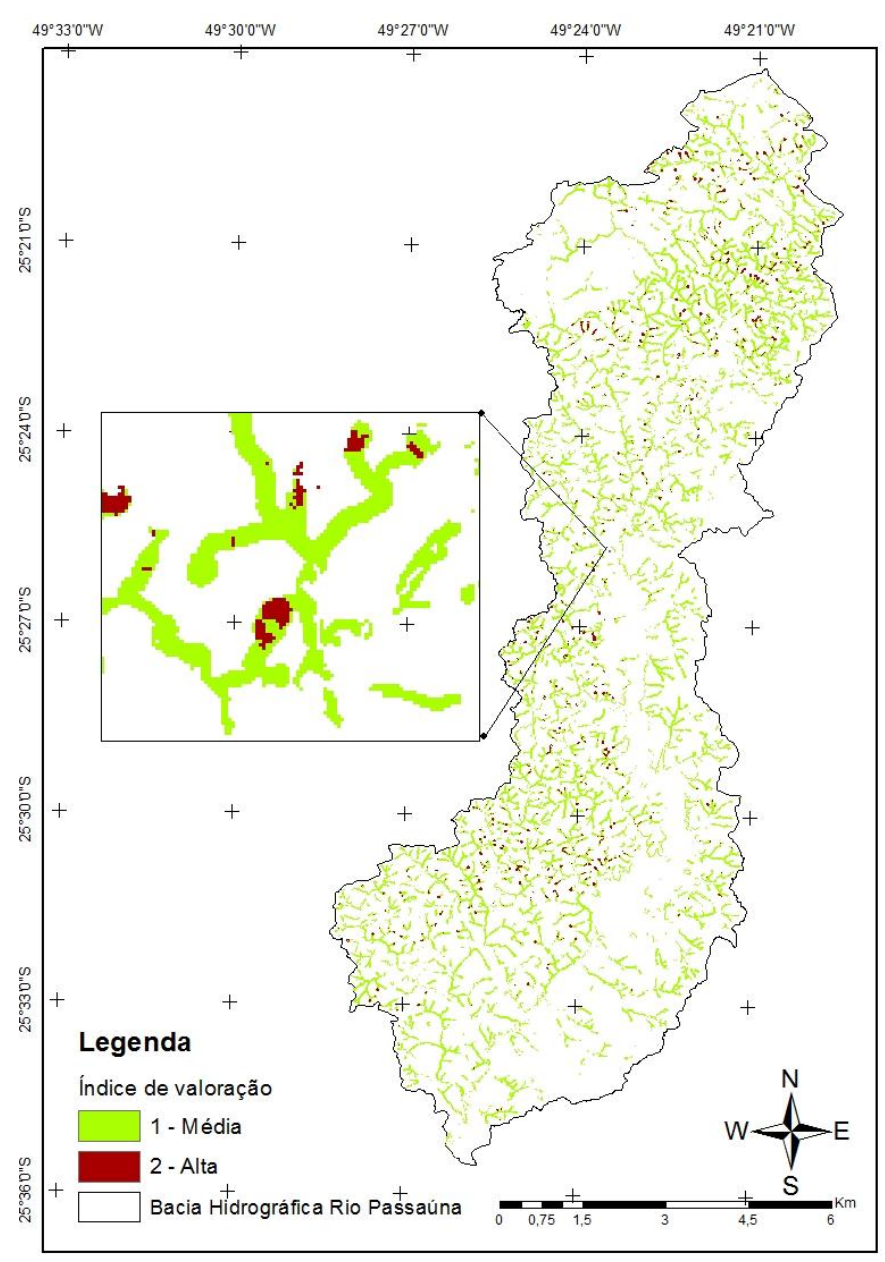

Figura 3. Mapa com as Áreas de Preservação Permanente prioritárias na Bacia Hidrográfica do Rio Passaúna.

Figure 3. Permanent preservation priority map areas of the Passaúna river watershed.

Tabela 5. Classificação e quantificação monetárias das Áreas de Preservação Permanente na Bacia Hidrográfica do Rio Passaúna.

Table 5. Monetary classification and quantification of permanent preservation areas in the Passaúna river watershed.

\begin{tabular}{lccc}
\hline Classificação & Área (ha) & Valoração ambiental $(\mathrm{R} \$)$ & Prioridade \\
\hline 1 & 872,2 & $824.229,00$ & Média \\
2 & 204,9 & $193.630,5$ & Alta \\
Total & $1.077,1$ & $1.017 .859,5$ & - \\
\hline
\end{tabular}

Fonte: elaborada pelos autores.

Partindo da afirmação de que todas as áreas passíveis de supressão ou redução sejam conservadas, ou seja, mantidas conforme previsto no Código de 1965, o custo de oportunidade total para a manutenção de cada hectare é de $R \$ 945,00$ ha/ano, totalizando um valor anual de $R \$ 1.017 .859,50$ para a conservação das áreas da Bacia Hidrográfica do Rio Passaúna. O valor pode ser considerado expressivo, entretanto, acredita-se que a função dos serviços ambientais providos na área, de forma direta e indireta, apresenta uma grande importância para a saúde ambiental da bacia hidrográfica, principalmente na qualidade da água.

Esse valor se aproxima do que já é praticado em algumas iniciativas de Pagamento por Serviços Ambientais (PSA) em municípios brasileiros (JARDIM 2010, GUEDES \& SEEHUSEN 2011, FUNDAÇÃO FLORESTAL 2016). A quantia encontrada pode ser entendida como o valor em que o produtor rural deveria ser compensado e o valor mínimo dos serviços ambientais, baseado na disposição a receber revelada pelo produtor rural. Assim, esse valor serve de referência para implantação de políticas públicas que 
reconheçam e incentivem produtores rurais que conservam áreas de importantes funções ambientais em suas propriedades.

A valoração ambiental é uma ferramenta importante para a continuidade do uso sustentável dos recursos disponíveis nesta bacia hidrográfica. Por meio desta é possível planejar ações que contribuam para a sua preservação, das quais uma delas poderia ser a criação de um programa de pagamentos por serviços ambientais, o qual forneceria certa remuneração econômica para os proprietários rurais que se comprometam a manter, em acordo com a legislação, a cobertura vegetal de suas APPs, contribuindo assim para melhorar a qualidade ambiental da bacia hidrográfica. Conforme apontado por TAKENAKA et al. (2016), o financiamento de tais programas, este é um passo chave para sua implantação, pode ser propiciado de diferentes maneiras, dentre as quais estão a captação de recursos junto ao Comitê de Bacias Hidrográficas, ou junto ao município, bem como por meio de recursos provindos do ICMS Ecológico ou dos valores recebidos pelo contrato da Companhia de Abastecimento Público.

De acordo com SIMÕES \& ANDRADE (2016), a política dos serviços ambientais é um instrumento de estímulo à conservação e à manutenção da provisão de recursos naturais que busca uma relação diferente da tradicional visão de poluidor-pagador, prevista na legislação. O PSA é um mecanismo de estímulo à preservação ambiental por meio de pagamentos aos responsáveis por áreas de provisão, ou seja, não se espera sofrer o dano, antes se estimula a conservação.

No momento não existe um programa de pagamentos por serviços ambientais implementado na bacia hidrográfica estudada, visando garantir a provisão dos serviços ecossistêmicos. O processo de incentivo econômico à preservação ambiental pode ser útil para efetivar a conservação e promover a qualidade ambiental de todo o manancial, visto que este tem uma contribuição importante para o abastecimento público de água. Entretanto, esforços do governo na criação de políticas públicas que fomentem a implementação e regularização de programas desse âmbito são de fundamental importância.

De forma a contribuir com as decisões a serem tomadas pelos gestores públicos, o presente estudo apresenta resultados que possam colaborar na escolha de áreas prioritárias para receber projetos de pagamentos por serviços ambientais, bem como a sua valoração ambiental.

Existem diversas iniciativas vindas de políticas públicas (GUEDES \& SEEHUSEN 2011, PAGIOLA et al. 2012) que têm sido consideradas para o pagamento de serviços ambientais. No Brasil existem projetos de PSA baseados em políticas públicas, como o Programa Bolsa Verde em Minas Gerais, o Programa Produtor ES de Água no Espírito Santo, o Programa Mina D'água em São Paulo, o Projeto Produtores de Água em Extrema (MG), o Programa Produtor de Água do Rio Vermelho, em São Bento do Sul, SC, entre outros. Existem diversos focos para os serviços ecossistêmicos gerados através da conservação das propriedades, sendo as duas maiores áreas em âmbito nacional os de sequestro de carbono e o de conservação de recursos hídricos.

A criação e a implantação de projetos de PSA, nas experiências acima, aparecem associadas à necessidade de melhorar as condições de provisão de água, tanto em qualidade como em quantidade. Observa-se uma forte associação das políticas de pagamento por serviços ambientais aos atores locais, sobretudo produtores rurais. Este é um fator importante uma vez que o espaço rural é composto por pastagens e grandes plantações que muitas vezes acabam por desgastar o solo, compactá-lo e mudar a hidrologia local, aumentando a erosão por influência do escoamento superficial e diminuindo a qualidade da água que chega ao canal fluvial (LIMA et al. 2013). A implantação de pagamento pelo serviço ambiental hídrico associado às demandas de aumento da cobertura vegetal e conservação é um instrumento com potencial de auxílio à manutenção dos recursos hídricos.

\section{CONCLUSÃO}

De acordo com o Código Florestal de 1965, identificou-se um total de 2.942,64 ha de APPs nas margens de cursos d'água na bacia hidrográfica do rio Passaúna. Entretanto, ao considerar as alterações feitas no ano de 2012, a área a ser mantida legalmente cai para 1864,64 ha, evidenciando uma redução de 1077,1 ha.

A valoração ambiental de APP, subsidiada pelo uso de mapas temáticos, se mostrou viável, sendo estas importantes ferramentas de gestão que podem auxiliar no processo de tomada de decisão, pois fornecem subsídios técnicos que refletem a situação da cobertura vegetal na bacia hidrográfica estudada.

Considerando a conservação dos $1.077,1$ ha por meio da implementação de um programa de PSA, 0 valor de custo de oportunidade para manter as Áreas de Preservação Permanente Conforme a legislação do Código Florestal de 1965 corresponde, em média, a R\$1.017.859,5 por ano, ou R\$ 945,00 ha/ano. 
Por fim, conclui-se que a valoração ambiental pode facilitar consideravelmente no processo de gestão da bacia hidrográfica que utiliza direta ou indiretamente um recurso ambiental, bem como é referência para implantação de políticas públicas que reconhecem e incentivem produtores rurais a conservar áreas com importantes funções ambientais em suas propriedades.

\section{REFERÊNCIAS}

ANDRADE DC et al. 2012. Dinâmica do uso do solo e valoração de serviços ecossistêmicos: notas de orientação para políticas ambientais. Desenvolvimento e Meio Ambiente 25: 53-71.

BRASIL. 1965. Lei o 4.771, de 15 de setembro de 1965. Institui o Código Florestal Brasileiro. Disponível em: http://www.planalto.gov.br/ccivil_03/Leis/L4771.htm. Acesso em: 16 nov. 2016.

BRASIL. 2012. Lei no 12.651, de 25 de maio de 2012. Dispõe sobre a proteção da vegetação nativa. Disponível em: http://www.planalto.gov.br/ccivil_03/_ato2011-2014/2012/lei//12651.htm. Acesso em: 16 nov. 2016.

DAILY GC et al. 2000. The value of nature and the nature of value. Science 289: 395-396.

DALY H E. 1991. A economia ecológica e o desenvolvimento sustentável. Rio de Janeiro: AS-PTA. 21p. (Textos para Debate, 34).

DEPARTAMENTO DE ECONOMIA RURAL. 2016. Estado do Paraná. Biblioteca Virtual - Preços. Disponível em: http://www.agricultura.pr.gov.br/. Acesso em: 15 nov. 2016.

ERNST C. 2004. Protecting the Source: Land Conservation and the Future of America's Drinking Water. Trust for Public Land. Washington D.C: $52 p$.

FRANCISCO CES. 2006. Áreas de preservação permanente na bacia do ribeirão das anhumas: estabelecimento de prioridades para recuperação por meio de análise multicriterial. Dissertação (Mestrado em Agricultura Tropical e Subtropical). Campinas: IAC. 108p.

FREITAS KAA et al. 2010. Valoração econômica dos benefícios ambientais percebidos pela população da bacia do Educandos provenientes do PROSAMIM. Acta Amazonica 40: 509-514.

FUNDAÇÃO FLORESTAL. 2016. Secretaria do Meio Ambiente de São Paulo. Programa nascentes. Disponível em: http://www.ambiente.sp.gov.br/programanascentes/. Acesso em: 12 dez. 2016.

GUEDES FB \& SEEHUSEN SE. 2011. Pagamentos por serviços ambientais na Mata Atlântica: lições aprendidas e desafios. Brasília: Ministério do Meio Ambiente. 272p. (Série Biodiversidade, 42).

INSTITUTO DAS ÁGUAS DO PARANÁ. 2000. Biblioteca Virtual - Mapas e dados espaciais. Disponível em: http://www.aguasparana.pr.gov.br/. Acesso em: 27 set. 2016.

JARDIM MH. 2010. Pagamentos por Serviços Ambientais na Gestão de Recursos Hídricos: O Caso do Município de Extrema - MG. Dissertação (Mestrado em Desenvolvimento Sustentável). Brasília: UnB. 195p.

JUSTINIANO MAF. 2010. Pagamento pelos Serviços Ambientais: Proteção das APP's através do ICMS ecológico. Dissertação (Mestrado em Direito Agrário). Goiânia: UFG. 149p.

KREUTER UP et al. 2001. Change in ecosystem service values in San Antonio area, Texas. Ecological Economics 39 : 333-346.

LIMA APM et al. 2013. Pagamento por serviços ambientais hídricos no Brasil: experiências iniciais e os desafios do monitoramento. Anais... In: 20 Simpósio Brasileiro de Recursos Hídricos. Água - Desenvolvimento Econômico e Ambiental. Bento Gonçalves: ABRH. 9p.

MOTTA RS da. 1998. Manual para valoração econômica de recursos ambientais. Brasília, DF: Ministério do Meio Ambiente, dos Recursos Hídricos e da Amazônia Legal. 216p.

NADIR JÚNIOR AM. 2006. ICMS Ecológico: Princípios e estratégias necessárias para uma implementação na coprodução do bem público. Dissertação (Mestrado em Administração) Florianópolis: UDESC. 133p.

PAGIOLA S et al. 2012. Experiências de pagamentos por serviços ambientais no Brasil. São Paulo: SMA/CBRN. 274p.

POSTEL SL \& THOMPSON JR. BH. 2005. Watershed protection: capturing the benefits of nature's water supply services. Natural Resources Forum 29: 98-108.

RIBEIRO CAAS et al. 2010. Valoração das Áreas de Preservação Permanente na Bacia do Rio Alegre - ES. Floresta e Ambiente 17: 63-72.

SANTA CATARINA. 2010. Lei no 15.133, de 19 de janeiro de 2010. Institui a Política Estadual de Serviços Ambientais e regulamenta o Programa Estadual de Pagamento por Serviços Ambientais no Estado de Santa Catarina. Disponível em: http://www.portaldoservidor.sc.gov.br/ckfinder/userfiles/arquivos/Legislacao\%20

Correlata/Leis\%20Ordinarias/2010_-_LEI_N\%C2\%BA_15_133,_de_19_de_janeiro_de_2010.pdf. Acesso em: 07 nov. 2016.

SAUNITI RM et al. 2004. Estudo do assoreamento do reservatório da barragem do Rio Passaúna - Curitiba - PR. Boletim Paranaense de Geociências 54: 65-82.

SILVA FILHO LV da. 2010. Qualidade e percepção ambiental: estudo de caso da Bacia Hidrográfica do Rio Passaúna. Dissertação (Mestrado em Engenharia de Recursos Hídricos e Ambiental). Curitiba: UFPR. 202p.

SIMÕES MS \& ANDRADE DC. 2016. Revisitando a teoria e compreendendo a prática: análise de casos de pagamento por serviços ambientais. Revista de Políticas Públicas 20: 903-926.

SPÖRL C \& ROSS JLS. 2004. Análise comparativa da fragilidade ambiental com aplicação de três modelos. GEOUSP Espaço e Tempo 15: 39-49. 
SUDERHSA. 2002. Superintendência de Desenvolvimento de Recursos Hídricos e Saneamento Ambiental. Relatório capacidade do sistema atual e medidas de controle de cheias. Modelagem das linhas de inundação da Bacia do rio Passaúna. Curitiba: SUDERHSA. 119p.

TAKENAKA EMM et al. 2016. Pagamento por serviços ambientais: apontamentos sobre o ICMS ecológico como instrumento de fomento a políticas públicas ambientais no Brasil. South American Development Society Journal 2: 8399.

VILAR MB et al. 2010. Valoração ambiental de propriedades rurais de municípios da Bacia Hidrográfica do Rio Xopotó, MG. Cerne 16: 539-545. 